\title{
PERSPECTIVE
}

\section{Learning from lorcaserin: lessons from the negative clinical trial of lorcaserin to treat cocaine use disorder}

\author{
S. Stevens Negus ${ }^{1}$ and Matthew L. Banks ${ }^{1}$ \\ Neuropsychopharmacology (2020) 45:1967-1973; https://doi.org/10.1038/s41386-020-00815-4
}

\begin{abstract}
"You can't let your failures define you. You have to let your failures teach you."
\end{abstract}

(Barack Obama)

The National Institute on Drug Abuse (NIDA) recently completed a Phase 2 clinical trial to evaluate the serotonin 5$\mathrm{HT}_{2 \mathrm{C}}$ receptor agonist lorcaserin as a pharmacotherapy for cocaine use disorder (CUD), and at present, the only publicly available data are posted on https://clinicaltrials.gov/ct2/show/ study/NCT03007394. The results are negative; the study did not show any significant difference between lorcaserin and placebo. The primary outcome measure for this study was the proportion of participants achieving self-reported abstinence confirmed by negative urine samples during the last 3 weeks of the 13-week trial. Only 1 of the 91 lorcaserin-treated participants who completed the trial met the abstinence criterion compared to 4 of 91 completers in the placebo group. Additional analyses are ongoing in subsets of participants and on outcomes of reduced cocaine use as opposed to abstinence, and a more detailed picture of lorcaserin effects on cocaine use will emerge as these analyses are completed and published by NIDA. Nonetheless, the trial was notable for its large size ( 272 total participants, 182 completers), its execution across 12 sites in 7 states and the District of Columbia, and its strong experimental design, which included not only a placebo control and triple blinding (of participants, care providers, and investigators), but also strategies to monitor and encourage compliance with the treatment regimen. The negative results, together with the withdrawal of lorcaserin as a weight-loss drug due to concerns about increased cancer risk [1, 2], suggest that lorcaserin will not gain approval as a CUD treatment.

Of course, the lorcaserin trial was not intended to fail. Lorcaserin's advancement to a Phase 2 clinical trial capped more than a decade of preclinical research that framed a plausible mechanistic hypothesis supported by a substantial body of preclinical data from laboratory animals [3-5]. These preclinical findings were generally interpreted to predict that lorcaserin maintenance had potential to safely and effectively decrease cocaine use and relapse by humans; hence the clinical trial. However, rather than fulfilling this prediction, the trajectory of translational research with lorcaserin to treat CUD seems destined to resemble the failed translation of other candidate medications for other disorders, e.g., [6]. The question we can begin to ask now is this: what will this failure in translation teach us. This Perspectives article focuses on two lessons and suggests a range of possible future directions.

\section{LESSON 1: "ANTAGONIST" MEDICATIONS HAVE A POOR TRACK RECORD AS CANDIDATE CUD MEDICATIONS}

Two major categories of substance use disorder treatments have been described as "antagonist" medications intended to block effects of the abused drug and "agonist" medications intended to mimic effects of the abused drug [7, 8]. In the treatment of opioid use disorder, the mu opioid receptor antagonist naltrexone is the prototype antagonist medication, whereas the high-efficacy mu agonist methadone is the prototype agonist medication. The ascent of lorcaserin as a candidate CUD treatment was founded on behavioral neuroscience studies interpreted to suggest that it might functionally antagonize effects that underlie cocaine's abuse potential $[3,5]$. Specifically, the monoamine neurotransmitters dopamine (DA), norepinephrine, and serotonin (5-HT) are cleared from the extracellular space by presynaptic transporter proteins. Cocaine binds to and blocks all three transporters to prevent monoamine uptake and increase extracellular monoamine concentrations, but cocaine-induced increases in DA concentrations at the terminals of mesolimbic DA neurons projecting from ventral tegmental area (VTA) to nucleus accumbens (NAC) are thought to be especially important for cocaine's high abuse potential. Lorcaserin does not bind to monoamine transporters, but instead functions as an agonist at serotonin 5$\mathrm{HT}_{2 \mathrm{C}}$ receptors. These are $\mathrm{G}_{\mathrm{q}}$-coupled receptors whose activation generally increases neuronal excitability, and among their other locations and functions, they are located on inhibitory gamma aminobutyric acid (GABA) neurons in VTA that innervate and inhibit mesolimbic DA neurons. Both electrophysiological and neurochemical studies have found that $5-\mathrm{HT}_{2} \mathrm{C}$ agonists activate these VTA GABA neurons, inhibit mesolimbic DA neurons, and attenuate cocaine-induced increases in NAc DA. This effectiveness of $5-\mathrm{HT}_{2 \mathrm{C}}$ agonists to attenuate cocaine-induced enhancement of NAC DA signaling suggested that lorcaserin or other $5-\mathrm{HT}_{2 \mathrm{C}}$ agonists might also be useful to block abuse-related behavioral effects of cocaine and be useful for treating CUD [3,5].

Although this type of antagonist approach is superficially plausible, lorcaserin is just the latest in a series of antagonistbased strategies to fail in humans as candidate CUD medications. Previous examples include: (1) "DA-sparing cocaine antagonists" (intended to bind DA transporters and have no effect on DA transport themselves while blocking cocaine binding to and inhibition of DA transporters, e.g., [9]), (2) DA receptor antagonists (intended to block effects of cocaine-enhanced extracellular DA at DA receptors [7]), and (3) kappa opioid receptor agonists (intended to bind $\mathrm{G}_{\mathrm{i}}$-coupled kappa receptors on mesolimbic DA neurons to inhibit activity and DA release from those neurons, e.g.,

${ }^{1}$ Department of Pharmacology and Toxicology, Virginia Commonwealth University, Richmond, VA 23298, USA

Correspondence: S. Stevens Negus (sidney.negus@vcuhealth.org)

Received: 15 July 2020 Revised: 10 August 2020 Accepted: 12 August 2020

Published online: 24 August 2020 
[10]). To our knowledge, the concept of a viable DA-sparing cocaine antagonist remains a theoretical possibility that has yet to be realized, and as a result, no drugs in this class have advanced to testing in humans. However, as with lorcaserin, both DA receptor antagonists and kappa receptor agonists advanced at least as far as human laboratory studies and failed to reduce cocaine intake up to medication doses that produced undesirable side effects. Accordingly, one cumulative lesson from decades of CUD medication development would appear to be that antagonist approaches have been consistently ineffective.

A full consideration of the basis for poor performance by candidate CUD antagonist medications is beyond the scope of this commentary, but one contributing factor will be mentioned here: antagonist medications designed to block effects of cocaineenhanced DA signaling can also impede basal DA signaling in the absence of cocaine. This basal DA signaling in the mesolimbic and nigrostriatal pathways is essential for normal movement, normal mood, and normal reinforcement learning maintained by nondrug reinforcers such as food, sex, and social interaction [11]. CUD itself impairs basal DA signaling [12], and further decreases in DA signaling produced by antagonist medications can exacerbate this hypodopaminergic state to produce dose-limiting side effects. A challenge in developing an effective antagonist medication for treating any substance use disorder is identification of antagonist dosing regimens that block reinforcing effects of the abused drug without blocking essential endogenous neurotransmission involving the receptor to which the abused drug binds. In the case of opioid use disorder, relatively high doses of antagonists like naltrexone can be used because basal signaling in opioid systems is low and opioid receptor blockade has relatively modest effects, but even here, undesirable effects are sufficient to impede compliance with therapeutically effective naltrexone treatment regimens, rendering naltrexone ineffective for most opioid use disorder patients $[13,14]$. In the case of CUD, basal DA signaling is higher, interruption of basal DA signaling is more problematic, and medication strategies have yet to be identified that can effectively block effects of cocaine-enhanced DA without also producing problematic disruption of basal DA signaling.

\section{LESSON 2: DRUG-CHOICE PROCEDURES CAN IMPROVE TRANSLATION IN CUD MEDICATION DEVELOPMENT}

The promotion of lorcaserin to a multi-site clinical trial depended not only on a plausible mechanistic hypothesis, but also on supportive preclinical data from many types of behavioral procedures routinely used in laboratory animals to assess candidate medications for substance use disorders [4]. A full description of the different types of behavioral procedures is beyond the scope of this commentary (for reviews, see [15-18]), but the most important have been versions of drug selfadministration procedures, in which rodents or nonhuman primates responded on a lever or response key to receive intravenous cocaine infusions, and lorcaserin was evaluated for its effectiveness to decrease cocaine-maintained responding. In one study, for example, rhesus monkeys were trained to press a lever under a fixed-ratio 30 schedule of cocaine self-administration (i.e., 30 lever presses for each injection) during daily 90-min sessions [19]. Once responding stabilized, monkeys were treated with a range of intragastric lorcaserin doses administered 90 min before session onset, and each lorcaserin dose was evaluated for 14 consecutive days. Lorcaserin produced a dose-dependent decrease in both rates of responding and in the number of cocaine injections earned per session. This decrease in cocaine self-administration was apparent on the 1st day of treatment and sustained throughout the 14-day treatment period. In addition, in separate groups of monkeys, the lorcaserin dose $(3.2 \mathrm{mg} / \mathrm{kg})$ that significantly reduced cocaine self-administration did not significantly decrease overall activity (assessed with accelerometers attached to the monkeys' collars), altered only one of 24 other observed behaviors (an increase in yawning), and produced a significant but small decrease in operant responding maintained by a non-drug reinforcer (food pellets). Overall, the results were interpreted to be "...consistent with the view that [lorcaserin] might have utility in treating cocaine abuse" [19]. Table 1 summarizes results from several other studies interpreted to be supportive of this view.

This preponderance of preclinical data and the interpretations they inspired failed to predict the definitively negative outcome of the clinical trial. However, Table 1 also shows that one preclinical research approach was predictive of clinical results. Specifically, studies in rhesus monkeys and humans that evaluated lorcaserin effects on choice between cocaine and an alternative nondrug reinforcer (food in monkeys, money in humans) found no effect of lorcaserin on cocaine choice $[20,21]$. The study in monkeys concluded that results "...do not support the clinical utility of 5$\mathrm{HT}_{2 \mathrm{C}}$ agonists as candidate anti-cocaine use disorder pharmacotherapies" [20]. The study in humans concluded that results "... do not support a direct therapeutic benefit on drug-reinforced behavior for the currently marketed dose of lorcaserin" [21]. Cocaine-vs.-food choice procedures have also predicted negative results with other candidate antagonist medications, including DA receptor antagonists and kappa opioid receptor agonists [22-26], as well as positive results with amphetamine maintenance (an "agonist" medication [7, 27, 28]) and a host of environmental manipulations that are known to modify clinical drug use and have been incorporated into treatment strategies such as contingency management [23, 29-38]. Taken together, these findings suggest that drug-choice procedures in both laboratory animals and humans may improve preclinical-to-clinical translation of effects with candidate CUD medications by virtue of combining both sensitivity to effective treatments and selectivity for effective vs. ineffective treatments.

Two features of drug-choice procedures may contribute to their utility for translational research on medications development for CUD and other substance use disorders $[30,39,40]$. The first is the primary dependent variable: drug choice. Most of the drug selfadministration procedures represented in Table 1 provide access at any given time to only a single reinforcer option (i.e., only cocaine), and the primary dependent variable is a measure of drug self-administration rate. Rates of drug self-administration in these single-option procedures can be decreased by treatments that produce the intended decrease in drug reinforcement, but drug self-administration rates can also be decreased by treatments that produce undesirable impairment of motor function, cognition, or general motivation. In contrast, choice procedures provide simultaneous access to two different reinforcer options (e.g., drug vs. food in laboratory animals, drug vs. money in humans), and the primary dependent variable is a measure of behavioral allocation between those two options. Effective treatments not only decrease drug choice, but also promote behavioral reallocation and increased choice of the nondrug alternative. Choice procedures also measure overall rates of operant behavior as a secondary dependent variable, and these two dependent variables facilitate interpretation of treatment effects. Treatments that produce a desirably selective decrease in reinforcing effects of the abused drug will decrease drug choice and increase choice of the nondrug alternative without decreasing overall behavioral rate. Conversely, treatments that produce motor/cognitive/motivational impairment without altering reinforcing effects of the abused drug will decrease overall rates without altering drug choice. Lorcaserin produced this latter profile of effects in drugchoice procedures $[20,21]$.

A second feature of choice procedures that promotes translational validity is that human drug abuse occurs in complex environments containing both drug and nondrug reinforcers, and a goal of any drug abuse treatment is not only to reduce drug use, 


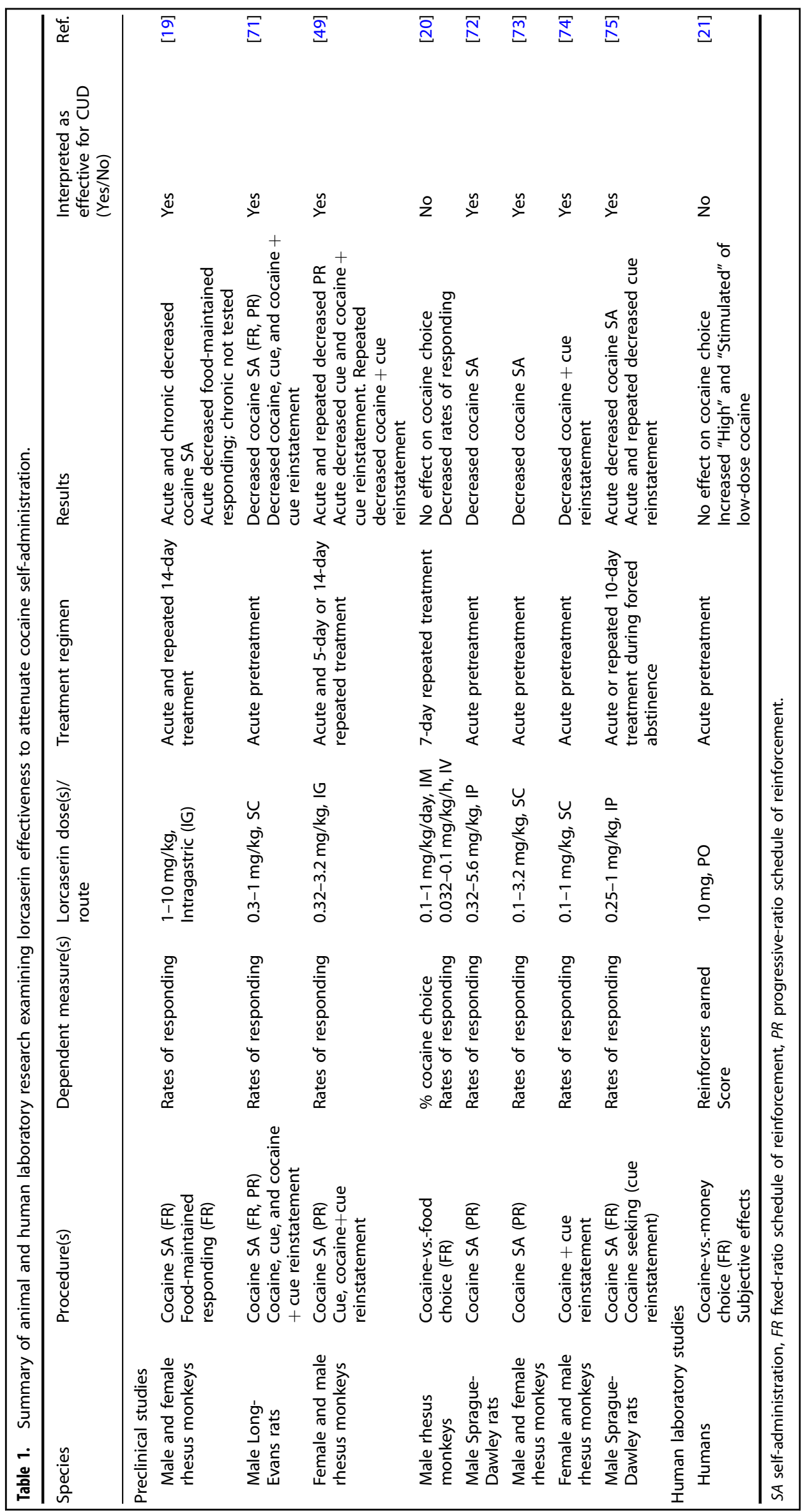


but also to increase more adaptive behaviors maintained by nondrug reinforcers [8]. Choice procedures provide a simplified but powerful tool for investigating medication effects on behavioral allocation in animal or human laboratory settings.

\section{FUTURE DIRECTIONS}

Completion of the Phase 2 clinical trial with lorcaserin is only the latest milestone in an ongoing effort to discover safe and effective medications for substance use disorders in general and CUD in particular. This effort will continue, and here we consider four possible future directions. First, one likely direction of future research will be founded on the interpretation that, despite its many strengths, the recently completed clinical trial was not adequate to test lorcaserin as a CUD treatment. Clinical trials can fail for many reasons other than lack of medication efficacy, and possible reasons for failure in this case will certainly be explored. These include (1) inadequate compliance with the intended dosing regimen [41], (2) focus on a rigorous primary outcome measure (abstinence for the final 3 weeks of the trial) that may have missed clinically relevant decreases in cocaine use [42], and (3) clinical testing of a lorcaserin dose $(10 \mathrm{mg} / \mathrm{kg}$ twice a day; equivalent to $0.35 \mathrm{mg} / \mathrm{kg} /$ day in a $70 \mathrm{~kg}$ human) lower than that found to be effective in preclinical studies (e.g., $3.2 \mathrm{mg} / \mathrm{kg} /$ day for rhesus monkeys in [19]). The first two of these issues can be explored by data mining in the current data set, whereas the third issue would require new clinical trials with higher lorcaserin doses. New studies with higher lorcaserin doses are unlikely given concerns about cancer risk and evidence for emergence of undesirable effects at higher lorcaserin doses in humans [43]; however, lorcaserin was selected for the clinical trial in part because it had been developed and approved independently for a different clinical indication (treatment of obesity) $[44,45]$. Other 5$\mathrm{HT}_{2 \mathrm{C}}$ agonists with higher selectivity for $5-\mathrm{HT}_{2} \mathrm{C}$ receptors vs. other targets (e.g., 5- $\mathrm{HT}_{2 \mathrm{~A}}$ receptors) are available as alternatives to lorcaserin, and positive allosteric modulators have also been developed [46]. Studies with new $5-\mathrm{HT}_{2 \mathrm{C}}$ ligands would also require new clinical trials as well as a more general commitment to the ill-fated "antagonist" strategy for CUD treatment.

A second direction of future research will be continued assessment of $5-\mathrm{HT}_{2} \mathrm{C}$ agonists as candidate treatments for other substance use disorders. The strongest evidence for lorcaserin effectiveness to treat substance abuse is for tobacco use disorder. Although lorcaserin was ineffective to promote abstinence from cocaine use, a randomized, double-blind, and placebo-controlled clinical trial found that a similar lorcaserin treatment regimen (10 $\mathrm{mg} / \mathrm{kg}$ BID for 12 weeks) was effective to promote smoking cessation [47]. Effects of lorcaserin or other $5-\mathrm{HT}_{2 \mathrm{C}}$ agonists on nicotine/tobacco choice have not been examined in animal or human laboratory studies, but lorcaserin did decrease nicotine self-administration in single-option procedures measuring selfadministration rates (reviewed in [44]). Lorcaserin has also been evaluated in preclinical assays of opioid, alcohol, and methamphetamine self-administration. Table 2 summarizes lorcaserin effects on opioid self-administration, and as with cocaine, lorcaserin decreased opioid self-administration in single-option procedures measuring self-administration rates in laboratory animals, but it failed to decrease opioid choice in rats, rhesus monkeys, or humans. Insofar as this profile of lorcaserin effects on opioid self-administration and choice is similar to the profile of lorcaserin effects on cocaine self-administration and choice, these results suggest that lorcaserin will not be effective to treat opioid use disorder. Lastly, lorcaserin decreased both alcohol consumption in rats [48] and methamphetamine self-administration in monkeys [49]. Lorcaserin was modestly more potent to decrease ethanol than water or sucrose consumption in rats, and this decrease was sustained over 10 days of treatment. In contrast, methamphetamine self-administration by monkeys was decreased

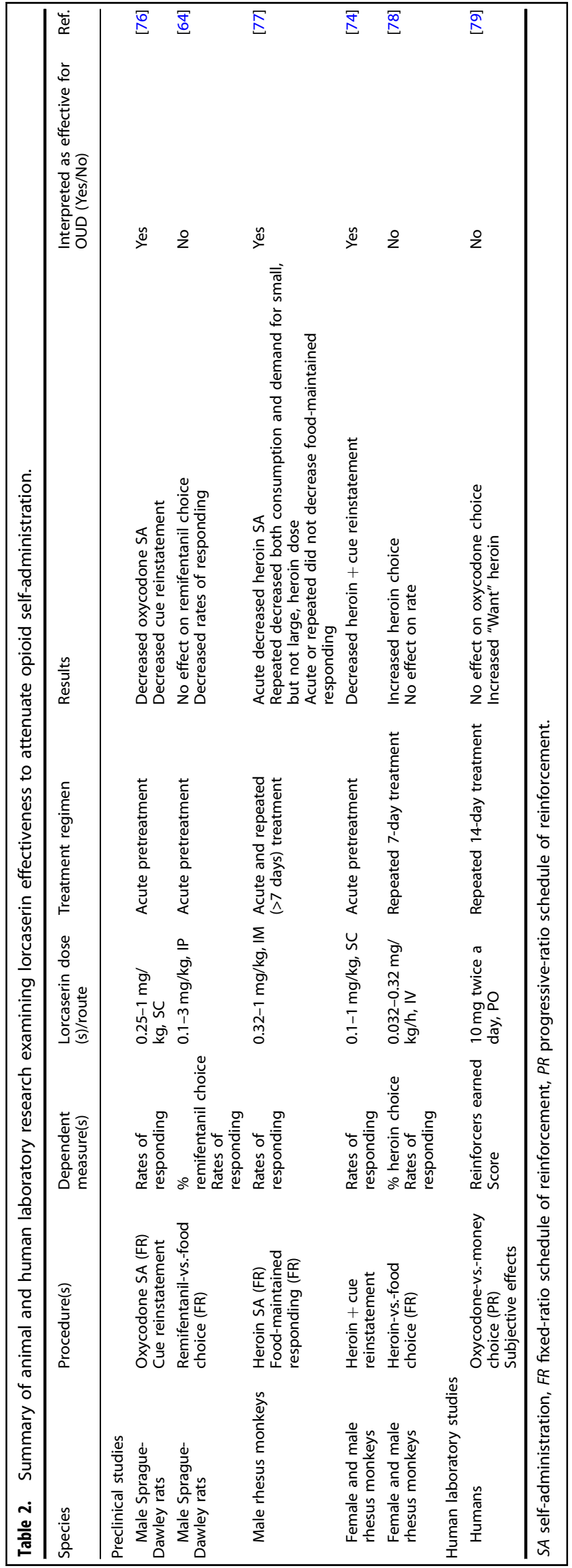


only by high lorcaserin doses that also decreased food-maintained responding, and tolerance developed rapidly to lorcaserininduced decreases in methamphetamine self-administration. As with CUD, any future studies for other substance use disorders would involve a commitment to an "antagonist" strategy and would likely need to use a different $5-\mathrm{HT}_{2 \mathrm{C}}$ ligand given the cancer risk associated with lorcaserin.

A third future direction could be to reallocate federally funded research from "antagonist" strategies for CUD treatment to "agonist" strategies or other approaches. Research on treatments for substance use disorders has long favored antagonist approaches, e.g., [50], but as summarized above, this approach has a poor track record for treatment of CUD. "Agonist" approaches have been more controversial but more effective for achieving clinical goals in treatment of opioid abuse (methadone and buprenorphine $[51,52]$ ) and nicotine/tobacco abuse (nicotine formulations, varenicline [53]), and the most effective treatment identified so far for CUD has been amphetamine maintenance $[7,28,54]$. Continued research to understand, implement, and improve agonist-based medications for CUD would seem to be justified $[27,55]$. Other approaches are also possible, such as strategies to alleviate or reverse hyperkatifeia induced by drug abuse and withdrawal [56].

In our view, a final direction of future research should be further development and integration of drug-choice procedures into preclinical medications-development research. Drug-choice procedures in rhesus monkeys and humans predicted failure of lorcaserin to produce abstinence from cocaine in the clinical trial. Moreover, drug-vs.-food choice procedures in both rats and rhesus monkeys yielded results consistent with the failure of lorcaserin to modify heroin-vs.-money choice in a human laboratory study. These findings agree with other evidence to suggest that drugchoice procedures in laboratory animals may be useful in reducing false-positive effects in the medications development pipeline of preclinical-to-clinical translational substance use disorder research $[16,30]$. For this reason, we propose that drug-choice procedures could play a key role in prioritization of candidate medications for advancement to essential but costly clinical trials.

In addition, the utility of drug-choice procedures could be extended beyond medications development to research on basic mechanisms of drug abuse [55]. Just as single-option selfadministration procedures are vulnerable to false-positive effects with candidate medications, so they are also vulnerable to falsepositive effects in mechanistic research with commonly used manipulations such as site-specific drug treatments, lesions, or optogenetic/chemogenetic modulation of neural circuits. Preclinical choice procedures could improve translation of results from such studies while also encouraging research on topics inaccessible to single-option procedures, such as vulnerability to drug abuse resulting from impaired sensitivity to alternative reinforcers. Lastly, while drug-choice studies in laboratory animals were initially developed in nonhuman primates using food as the alternative nondrug reinforcer [23, 29, 33, 57-59], technical advances have now enabled development of drug-vs.-food choice procedures in rats [60-69] and development of procedures that use social reinforcement rather than food as the alternative nondrug reinforcer [70]. These advances open new and exciting opportunities in the use of drug-choice procedures for both improving basic knowledge of substance use disorders and developing new medications for their treatment.

\section{FUNDING AND DISCLOSURES}

The authors' research was supported by the National Institute on Drug Abuse of the National Institutes of Health under Award Numbers R01DA026946 and UH3DA041146. The National Institute on Drug Abuse had no role in the writing or decision to submit the paper for publication. The paper content is solely the responsibility of the authors and does not necessarily reflect the official views of the National Institutes of Health. All authors declare their research has been funded by the NIH. The authors declare no competing interests.

\section{AUTHOR CONTRIBUTIONS}

Both authors contributed to the conceptualization and writing of the paper.

\section{ADDITIONAL INFORMATION}

Publisher's note Springer Nature remains neutral with regard to jurisdictional claims in published maps and institutional affiliations.

\section{REFERENCES}

1. US_Food_and_Drug_Administration. FDA requests the withdrawal of the weightloss drug Belviq, Belviq XR (lorcaserin) from the market: potential risk of cancern outweighs the benefits. https://www.fda.gov/drugs/drug-safety-and-availability/ fda-requests-withdrawal-weight-loss-drug-belviq-belviq-xr-lorcaserin-market. Accessed 13 Feb 2020.

2. Kumar R, Ryan D. Lorcaserin departs, leaving more questions than answers. Obesity. 2020;28:1167. https://doi.org/10.1002/oby.22789.

3. Bubar MJ, Cunningham KA. Prospects for serotonin $5-\mathrm{HT} 2 \mathrm{R}$ pharmacotherapy in psychostimulant abuse. Prog Brain Res. 2008;172:319-46. https://doi.org/10.1016/ S0079-6123(08)00916-3.

4. Collins GT, Gerak LR, France CP. The behavioral pharmacology and therapeutic potential of lorcaserin for substance use disorders. Neuropharmacology. 2018;142:63-71. https://doi.org/10.1016/j.neuropharm.2017.12.023.

5. Howell LL, Cunningham KA. Serotonin 5-HT2 receptor interactions with dopamine function: implications for therapeutics in cocaine use disorder. Pharm Rev. 2015;67:176-97. https://doi.org/10.1124/pr.114.009514.

6. Yezierski RP, Hansson P. Inflammatory and neuropathic pain from bench to bedside: what went wrong? J Pain. 2018;19:571-88. https://doi.org/10.1016/j. jpain.2017.12.261.

7. Grabowski J, Shearer J, Merrill J, Negus SS. Agonist-like, replacement pharmacotherapy for stimulant abuse and dependence. Addict Behav. 2004;29:1439-64. https://doi.org/10.1016/j.addbeh.2004.06.018.

8. Vocci F, Ling W. Medications development: successes and challenges. Pharm Ther. 2005;108:94-108. https://doi.org/10.1016/j.pharmthera.2005.06.010.

9. Meltzer PC, Liu S, Blanchette H, Blundell P, Madras BK. Design and synthesis of an irreversible dopamine-sparing cocaine antagonist. Bioorg Med Chem. 2002;10:3583-91. https://doi.org/10.1016/s0968-0896(02)00244-4.

10. Walsh SL, Geter-Douglas B, Strain EC, Bigelow GE. Enadoline and butorphanol: evaluation of kappa-agonists on cocaine pharmacodynamics and cocaine selfadministration in humans. J Pharm Exp Ther. 2001;299:147-58.

11. Wise RA. Dopamine, learning and motivation. Nat Rev Neurosci. 2004;5:483-94. https://doi.org/10.1038/nrn1406.

12. Volkow ND, Fowler JS, Wang GJ, Goldstein RZ. Role of dopamine, the frontal cortex and memory circuits in drug addiction: insight from imaging studies. Neurobiol Learn Mem. 2002;78:610-24. https://doi.org/10.1006/nlme.2002.4099.

13. Comer SD, Collins ED, Kleber HD, Nuwayser ES, Kerrigan JH, Fischman MW. Depot naltrexone: long-lasting antagonism of the effects of heroin in humans. Psychopharmacol (Berl). 2002;159:351-60. https://doi.org/10.1007/s002130100909.

14. Sevarino, KA, Kosten, TR. In: Dean RL, Bilsky EJ, Negus SS, editors. Opiate receptors and antagonists. Ch. 12, 227-245. Humana Press, New York, NY; 2009.

15. Banks ML, Hutsell BA, Schwienteck KL, Negus SS. Use of preclinical drug vs. food choice procedures to evaluate candidate medications for cocaine addiction. Curr Treat Options Psychiatry. 2015;2:136-50. https://doi.org/10.1007/s40501-0150042-9.

16. Czoty PW, Stoops WW, Rush CR. Evaluation of the "pipeline" for development of medications for cocaine use disorder: a review of translational preclinical, human laboratory, and clinical trial research. Pharm Rev. 2016;68:533-62. https://doi.org/ 10.1124/pr.115.011668.

17. Haney M, Spealman R. Controversies in translational research: drug selfadministration. Psychopharmacology. 2008;199:403-19. https://doi.org/10.1007/ s00213-008-1079-x.

18. Mello NK, Negus SS. Preclinical evaluation of pharmacotherapies for treatment of cocaine and opioid abuse using drug self-administration procedures. Neuropsychopharmacology. 1996;14:375-424. https://doi.org/10.1016/0893-133X(95) 00274-H.

19. Collins GT, Gerak LR, Javors MA, France CP. Lorcaserin reduces the discriminative stimulus and reinforcing effects of cocaine in rhesus monkeys. J Pharm Exp Ther. 2016;356:85-95. https://doi.org/10.1124/jpet.115.228833. 
20. Banks ML, Negus SS. Repeated 7-day treatment with the 5-ht2c agonist lorcaserin or the 5-ht2a antagonist pimavanserin alone or in combination fails to reduce cocaine vs food choice in male rhesus monkeys. Neuropsychopharmacology. 2017;42:1082-92. https://doi.org/10.1038/npp.2016.259.

21. Pirtle JL, Hickman MD, Boinpelly VC, Surineni K, Thakur HK, Grasing KW. The serotonin-2C agonist lorcaserin delays intravenous choice and modifies the subjective and cardiovascular effects of cocaine: a randomized, controlled human laboratory study. Pharm Biochem Behav. 2019;180:52-9. https://doi.org/10.1016/ j.pbb.2019.02.010.

22. Czoty PW, Nader MA. Effects of dopamine D2/D3 receptor ligands on foodcocaine choice in socially housed male cynomolgus monkeys. J Pharm Exp Ther. 2013;344:329-38. https://doi.org/10.1124/jpet.112.201012.

23. Negus SS. Rapid assessment of choice between cocaine and food in rhesus monkeys: effects of environmental manipulations and treatment with damphetamine and flupenthixol. Neuropsychopharmacology. 2003;28:919-31. https://doi.org/10.1038/sj.npp.1300096.

24. Negus SS. Effects of the kappa opioid agonist U50,488 and the kappa opioid antagonist nor-binaltorphimine on choice between cocaine and food in rhesus monkeys. Psychopharmacology. 2004;176:204-13. https://doi.org/10.1007/s00213004-1878-7.

25. Thomsen M, Barrett AC, Butler P, Negus SS, Caine SB. Effects of acute and chronic treatments with dopamine D2 and D3 receptor ligands on cocaine versus food choice in rats. J Pharm Exp Ther. 2017;362:161-76. https://doi.org/10.1124/ jpet.117.241141.

26. Woolverton WL, Balster RL. Effects of antipsychotic compounds in rhesus monkeys given a choice between cocaine and food. Drug Alcohol Depend. 1981;8:69-78. https://doi.org/10.1016/0376-8716(81)90088-0.

27. Negus SS, Henningfield J. Agonist medications for the treatment of cocaine use disorder. Neuropsychopharmacology. 2015;40:1815-25. https://doi.org/10.1038/ npp.2014.322.

28. Tardelli VS, Bisaga A, Arcadepani FB, Gerra G, Levin FR, Fidalgo TM. Prescription psychostimulants for the treatment of stimulant use disorder: a systematic review and meta-analysis. Psychopharmacology. 2020;237:2233-55. https://doi.org/ 10.1007/s00213-020-05563-3.

29. Aigner TG, Balster RL. Choice behavior in rhesus monkeys: cocaine versus food. Science. 1978;201:534-5. https://doi.org/10.1126/science.96531.

30. Banks ML, Negus SS. Insights from preclinical choice models on treating drug addiction. Trends Pharm Sci. 2017;38:181-94. https://doi.org/10.1016/j. tips.2016.11.002

31. Caprioli D, Venniro M, Zeric T, Li X, Adhikary S, Madangopal R, et al. Effect of the novel positive allosteric modulator of metabotropic glutamate receptor 2 AZD8529 on incubation of methamphetamine craving after prolonged voluntary abstinence in a rat model. Biol Psychiatry. 2015;78:463-73. https://doi.org/ 10.1016/j.biopsych.2015.02.018.

32. Nader MA, Hedeker D, Woolverton WL. Behavioral economics and drug choice: effects of unit price on cocaine self-administration by monkeys. Drug Alcohol Depend. 1993;33:193-9.

33. Nader MA, Woolverton WL. Effects of increasing the magnitude of an alternative reinforcer on drug choice in a discrete-trials choice procedure. Psychopharmacology. 1991;105:169-74.

34. Nader MA, Woolverton WL. Choice between cocaine and food by rhesus monkeys: effects of conditions of food availability. Behav Pharm. 1992;3:635-8.

35. Nader MA, Woolverton WL. Effects of increasing response requirement on choice between cocaine and food in rhesus monkeys. Psychopharmacology. 1992;108:295-300. https://doi.org/10.1007/BF02245115.

36. Negus SS. Effects of punishment on choice between cocaine and food in rhesus monkeys. Psychopharmacology. 2005;181:244-52. https://doi.org/10.1007/ s00213-005-2266-7.

37. Thomsen M, Barrett AC, Negus SS, Caine SB. Cocaine versus food choice procedure in rats: environmental manipulations and effects of amphetamine. J Exp Anal Behav. 2013;99:211-33. https://doi.org/10.1002/jeab.15.

38. Venniro M, Zhang M, Caprioli D, Hoots JK, Golden SA, Heins C, et al. Volitional social interaction prevents drug addiction in rat models. Nat Neurosci. 2018;21:1520-9. https://doi.org/10.1038/s41593-018-0246-6.

39. Banks ML, Negus SS. Preclinical determinants of drug choice under concurrent schedules of drug self-administration. Adv Pharm Sci. 2012;2012:281768 https:// doi.org/10.1155/2012/281768.

40. Negus, SS, Banks, ML. In: Glennon RA, Young R, editors. Drug discrimination: applications to medicinal chemistry and drug studies, 361-88. John Wiley \& Sons, Hoboken, NJ; 2011.

41. McCann DJ, Petry NM, Bresell A, Isacsson E, Wilson E, Alexander RC. Medication nonadherence, "professional subjects," and apparent placebo responders: overlapping challenges for medications development. J Clin Psychopharmacol. 2015;35:566-73. https://doi.org/10.1097/JCP.0000000000000372.
42. Roos CR, Nich C, Mun CJ, Babuscio TA, Mendonca J, Miguel AQC, et al. Clinical validation of reduction in cocaine frequency level as an endpoint in clinical trials for cocaine use disorder. Drug Alcohol Depend. 2019;205:107648. https://doi.org/ 10.1016/j.drugalcdep.2019.107648.

43. Shram MJ, Schoedel KA, Bartlett C, Shazer RL, Anderson CM, Sellers EM. Evaluation of the abuse potential of lorcaserin, a serotonin $2 \mathrm{C}(5-\mathrm{HT} 2 \mathrm{C})$ receptor agonist, in recreational polydrug users. Clin Pharm Ther. 2011;89:683-92. https://doi. org/10.1038/clpt.2011.20.

44. Higgins GA, Fletcher PJ, Shanahan WR. Lorcaserin: a review of its preclinical and clinical pharmacology and therapeutic potential. Pharm Ther. 2020;205:107417. https://doi.org/10.1016/j.pharmthera.2019.107417.

45. Singh AK, Singh R. Efficacy and safety of lorcaserin in obesity: a systematic review and meta-analysis of randomized controlled trials. Expert Rev Clin Pharm. 2020;13:183-90. https://doi.org/10.1080/17512433.2020.1703109.

46. Wold EA, Wild CT, Cunningham KA, Zhou J. Targeting the $5-\mathrm{HT} 2 \mathrm{C}$ receptor in biological context and the current state of $5-\mathrm{HT} 2 \mathrm{C}$ receptor ligand development. Curr Top Med Chem. 2019;19:1381-98. https://doi.org/10.2174/156802661 9666190709101449.

47. Shanahan WR, Rose JE, Glicklich A, Stubbe S, Sanchez-Kam M. Lorcaserin for smoking cessation and associated weight gain: a randomized 12-week clinical trial. Nicotine Tob Res. 2017;19:944-51. https://doi.org/10.1093/ntr/ntw301.

48. Rezvani AH, Cauley MC, Levin ED. Lorcaserin, a selective 5-HT(2C) receptor agonist, decreases alcohol intake in female alcohol preferring rats. Pharm Biochem Behav. 2014;125:8-14. https://doi.org/10.1016/j.pbb.2014.07.017.

49. Gerak LR, Collins GT, France CP. Effects of lorcaserin on cocaine and methamphetamine self-administration and reinstatement of responding previously maintained by cocaine in rhesus monkeys. J Pharm Exp Ther. 2016;359:383-91. https://doi.org/10.1124/jpet.116.236307.

50. Campbell ND, Lovell AM. The history of the development of buprenorphine as an addiction therapeutic. Ann N Y Acad Sci. 2012;1248:124-39. https://doi.org/ 10.1111/j.1749-6632.2011.06352.x.

51. Dole VP, Nyswander M. A medical treatment for diacetylmorphine (heroin) addiction. A clinical trial with methadone hydrochloride. JAMA. 1965;193:646-50. https://doi.org/10.1001/jama.1965.03090080008002.

52. Jasinski DR, Pevnick JS, Griffith JD. Human pharmacology and abuse potential of the analgesic buprenorphine: a potential agent for treating narcotic addiction. Arch Gen Psychiatry. 1978;35:501-16. https://doi.org/10.1001/archpsyc.1978.01770280111012.

53. Fant RV, Buchhalter AR, Buchman AC, Henningfield JE. Pharmacotherapy for tobacco dependence. Handbook of experimental pharmacology, 487-510; 2009. https://doi.org/10.1007/978-3-540-69248-5_17.

54. Castells X, Cunill R, Perez-Mana C, Vidal X, Capella D. Psychostimulant drugs for cocaine dependence. Cochrane Database Syst Rev. 2016;9:CD007380. https://doi. org/10.1002/14651858.CD007380.pub4.

55. Venniro M, Banks ML, Heilig M, Epstein DH, Shaham Y. Improving translation of animal models of addiction and relapse by reverse translation. Nat Rev Neurosci. 2020.

56. Koob GF. Neurobiology of opioid addiction: opponent process, hyperkatifeia, and negative reinforcement. Biol Psychiatry. 2020;87:44-53. https://doi.org/10.1016/j. biopsych.2019.05.023.

57. Maguire DR, Gerak LR, France CP. Delay discounting of food and remifentanil in rhesus monkeys. Psychopharmacology. 2013;229:323-30. https://doi.org/ 10.1007/s00213-013-3121-x.

58. Griffiths RR, Wurster RM, Brady JV. Discrete-trial choice procedure: effects of naloxone and methadone on choice between food and heroin. Pharm Rev. 1975;27:357-65.

59. Spragg S. Morphine addiction in chimpanzees. Comp Psychol Monogr. 1940;15:5-132.

60. Ahmed SH. Trying to make sense of rodents' drug choice behavior. Prog Neuropsychopharmacol Biol Psychiatry. 2018;87:3-10. https://doi.org/10.1016/j. pnpbp.2017.09.027.

61. Beckmann JS, Chow JJ, Hutsell BA. Cocaine-associated decision-making: toward isolating preference. Neuropharmacology. 2019;153:142-52. https://doi.org/ 10.1016/j.neuropharm.2019.03.025

62. Carroll ME, Lac ST, Nygaard SL. A concurrently available nondrug reinforcer prevents the acquisition or decreases the maintenance of cocaine-reinforced behavior. Psychopharmacology. 1989;97:23-29. https://doi.org/10.1007/BF00443407.

63. Kerstetter KA, Duffin-Lutgen S, Carr AE, Behrens AM, Kippin TE. Sex differences in selecting between food and cocaine reinforcement are mediated by estrogen. Neuropsychopharmacology. 2012;37:2605-14. https://doi.org/10.1038/ npp.2012.99.

64. Panlilio LV, Secci ME, Schindler CW, Bradberry CW. Choice between delayed food and immediate opioids in rats: treatment effects and individual differences. Psychopharmacology. 2017;234:3361-73. https://doi.org/10.1007/s00213-0174726-2. 
65. Pelloux Y, Murray JE, Everitt BJ. Differential vulnerability to the punishment of cocaine related behaviours: effects of locus of punishment, cocaine taking history and alternative reinforcer availability. Psychopharmacology. 2015;232:125-34. https://doi.org/10.1007/s00213-014-3648-5.

66. Perry AN, Westenbroek C, Becker JB. The development of a preference for cocaine over food identifies individual rats with addiction-like behaviors. PLoS ONE. 2013;8:e79465. https://doi.org/10.1371/journal.pone.0079465.

67. Thomsen M, Fink-Jensen A, Woldbye DPD, Wortwein G, Sager TN, Holm R, et al. Effects of acute and chronic aripiprazole treatment on choice between cocaine self-administration and food under a concurrent schedule of reinforcement in rats. Psychopharmacology. 2008;201:43-53. https://doi.org/10.1007/s00213-0081245-1.

68. Townsend EA, Negus SS, Caine SB, Thomsen M, Banks ML. Sex differences in opioid reinforcement under a fentanyl vs. food choice procedure in rats. Neuropsychopharmacology. 2019;44:2022-9. https://doi.org/10.1038/s41386-0190356-1.

69. Tunstall BJ, Riley AL, Kearns DN. Drug specificity in drug versus food choice in male rats. Exp Clin Psychopharmacol. 2014;22:364-72. https://doi.org/10.1037/ a0037019.

70. Venniro $M$, Shaham Y. An operant social self-administration and choice model in rats. Nat Protoc. 2020;15:1542-59. https://doi.org/10.1038/s41596-020-0296-6.

71. Harvey-Lewis C, Li Z, Higgins GA, Fletcher PJ. The 5-HT(2C) receptor agonist lorcaserin reduces cocaine self-administration, reinstatement of cocaine-seeking and cocaine induced locomotor activity. Neuropharmacology. 2016;101:237-45. https://doi.org/10.1016/j.neuropharm.2015.09.028.

72. Gannon BM, Sulima A, Rice KC, Collins GT. Inhibition of cocaine and 3,4-methylenedioxypyrovalerone (MDPV) self-administration by lorcaserin is mediated by
5-HT2C receptors in rats. J Pharm Exp Ther. 2018;364:359-66. https://doi.org/ 10.1124/jpet.117.246082.

73. Collins GT, France CP. Effects of lorcaserin and buspirone, administered alone and as a mixture, on cocaine self-administration in male and female rhesus monkeys. Exp Clin Psychopharmacol. 2018;26:488-96. https://doi.org/10.1037/pha0000209.

74. Gerak LR, Collins GT, Maguire DR, France CP. Effects of lorcaserin on reinstatement of responding previously maintained by cocaine or remifentanil in rhesus monkeys. Exp Clin Psychopharmacol. 2019;27:78-86. https://doi.org/10.1037/ pha0000234.

75. Anastasio NC, Sholler DJ, Fox RG, Stutz SJ, Merritt CR, Bjork JM, et al. Suppression of cocaine relapse-like behaviors upon pimavanserin and lorcaserin coadministration. Neuropharmacology. 2020;168:108009. https://doi.org/10.1016/j. neuropharm.2020.108009.

76. Neelakantan H, Holliday ED, Fox RG, Stutz SJ, Comer SD, Haney M, et al Lorcaserin suppresses oxycodone self-administration and relapse vulnerability in rats. ACS Chem Neurosci. 2017;8:1065-73. https://doi.org/10.1021/acschemneuro. $6 \mathrm{~b} 00413$.

77. Kohut SJ, Bergman J. Lorcaserin decreases the reinforcing effects of heroin, but not food, in rhesus monkeys. Eur J Pharm. 2018;840:28-32. https://doi.org/ 10.1016/j.ejphar.2018.09.025.

78. Townsend EA, Negus SS, Poklis JL, Banks ML. Lorcaserin maintenance fails to attenuate heroin vs. food choice in rhesus monkeys. Drug Alcohol Depend. 2020;208:107848. https://doi.org/10.1016/j.drugalcdep.2020.107848.

79. Brandt L, Jones JD, Martinez S, Manubay JM, Mogali S, Ramey T, et al. Effects of lorcaserin on oxycodone self-administration and subjective responses in participants with opioid use disorder. Drug Alcohol Depend. 2020;208:107859. https:// doi.org/10.1016/j.drugalcdep.2020.107859. 